\title{
Adopting Open-ended Exercise And Self-study Modes To Implement Contextual Learning Approach To Enhance Engineering Knowledge/skills
}

Gururaj Fattepur $^{1}$, B.B.Kotturshettar ${ }^{2}$, B.S.Kakol ${ }^{3}$

${ }_{1,2,3}$ Dept. of Industrial and Production Engineering, BVBCET, Hubli, India

'gururaj_f@bvb.edu, ${ }^{2}$ bbkshettar@bvb.edu, ${ }^{3}$ bskakol@bvb.edu

\begin{abstract}
Contextual learning is one of the best ways to convey students the concepts that are being taught in a subject area to real industrial problems so that students are exposed to provide a real-world, product-based framework to integrate and expand the learning experiences from different courses and lab exercises and can enhance their engineering knowledge and skills. This innovative teaching learning process of Contextual Learning is being adopted in the Department of Industrial and Production Engineering for the students of third semester to eight semester and context of study is ASME \#150 Gate Valve. This paper focuses on adopting this practice for third and fourth semester students in understanding the generalised design procedure and assembly of valve. Activities were carried out through an open ended experiment in Engineering Design Lab of third semester and a Self study component in Design of Machine Elements at fourth semester to convey the modelling and design concepts of gate valve. This paper concludes with the challenges encountered for the continual improvement for adopting this method of learning.g.
\end{abstract}

\section{Gururaj Fattepur}

Dept. of Industrial and Production Engineering, BVBCET, Hubli, India gururaj_f@bvb.edu
Keywords - Integrated approach, product-based learning

\section{Introduction}

The main milestone in today's industrial engineering education is to integrate the concepts of product design, manufacturing and quality. The purpose of open ended experiments, course projects and self study components is to integrate and apply student knowledge is common practice, and with a known reason and with a fixed goal. The benefit obtained when students experience their knowledge in action is hard to understate. In order to integrate the industrial engineering curriculum and product based learning, the department of Industrial \& Production Engineering at BVBCET has adopted contextual learning from the academic year 2013-14, and the context of study is ASME \#150 Gate Valve.

ASME \#150 Gate Valves are of conventional full bore with flexible wedge that provides flexure of the gate seating surfaces. The two inclined seats allow for tight shut off even against high pressures. Outside Screw and yoke design aids some parts to be interchangeable to other valve types thus increasing the assembly flexibility. Gate valves are bi directional valves and of easy operation being widely used in power, chemical and oil industry. These valves are used for high temperature and high pressure service conditions, especially on power plants. Valves in corporate, standard hand wheel or, optionally, worm gears, pneumatic, electric, hydraulic and hydropneumatic actuators. 
Through a sequence of several existing courses, students design, document and build a number of complete valves. The project is being implemented by strengthening existing course delivery and lab exercises. This paper discusses the progress of the project and how it is being used to integrate various course works using open ended experiment and self study component to model and design the context of study.

\section{Scope}

The main scope of this project is to integrate the context of study with the various predefined lab and theory courses. The department of Industrial and Production Engineering at BVBCET has identified three manufacturing verticals for curriculum design namely System Design and Automation, Process and Tooling, and Management. As a part of this teaching practice, various lab and theory courses are identified through third to eight semesters to address the manufacturing verticals. In the present case of exercise, two courses from second year of engineering are identified under the Product Design verticals. Students took these exercises as a part of their open ended experiment in Engineering Design Lab course at third semester and Self study component of Design of Machine Elements course in fourth semester.

As they progress through their coursework, students experienced the valve project from various design perspectives. One of the major inputs to the development of valve is adherence to reference standards. Students refer the internet to gather information on ASME, API and other gate valve standard codes. This helped them to acquire the basic design knowledge on sizes, materials to be used, operating pressure range and other design factors, and also this created a curiosity among them to know various other products that need to be developed as per standard codes. They prepared working 2D drawings and $3 \mathrm{D}$ assembly models that may be used to create CNC machining programs, and they learned about tolerances that will later drive quality characteristics. Although the work was carried in two different semesters, each class was treated as if it was occurring simultaneously with the other activities, resulting in a tangible experience of concurrent engineering.

\section{Objectives}

The main objectives of this project undertaken are to enlighten students with the basic knowledge of industrial valves, their types, applications, design considerations and etc,

- recognise and identify the right measuring instrument to measure the disassembled parts of gate valve,

- enhance the usability and explore various commands of 3D modelling software by performing the detailed drawing, part modelling and assembly of gate valve,

- make understand students the significance of use of standards and codes in product design,

- understand the design considerations and design the basic parts of gate valve referring to standard API 60 .

\section{Methodology}

\section{A. Engineering Design Lab (3rd semester)}

In the third semester, students learn a lab course of "Engineering Design", where they are taught the concepts of 2D drawing, 3D part modelling and assembly using modelling software. This lab course is delivered through well designed exercises and an open ended exercise where students work in group and perform the desired task. General practice adopted for open ended exercise is that the students choose a model or a product of their choice, take their dimensions and perform the part modelling and assemble them. As a part of adopting contextual learning technique, students were given the task of performing the $3 \mathrm{D}$ modelling of gate valve through following activities:

a) Students were to carry out literature survey valve and valve types.

b) Further students were to collect details on gate valves, their construction, working principles and applications.

c) Groups of four or five students worked to disassemble the given gate valve assembly, identify the components and take their individual dimensions using micrometer screw gauge, vernier calipers and other measuring instruments (care was taken while noting the measurements of machined parts and casted parts).

d) Further student groups performed the 3D modelling of measured valve components in software, 
extracted the 2D drawings in different views and assembled the parts to obtain the final modelled gate valve assembly considering important tolerances. They also prepared Bill of Materials for the valve assembly.

\section{B. Design of Machine Elements (4th semester theory)}

In fourth semester students are taught a design subject "Design of Machine Elements" where they learn the design of standard machine components like gears, bearings, springs, welded joints, riveted joints, etc referring to standard design data handbook. With this course students gain the basic knowledge of applying different design equations referring from design data handbook to design and determine the dimensions of various components for different operating and loading conditions. This is a five credits course with one credit self study component. For this one credit self study component students are desired to learn the basic design procedure to determine the dimensions of parts of gate valve referring to codes and standards. This exercise was performed through following activities:

a) Student groups of five were to collect information on identifying the key design factors to be considered for a valve design and give a presentation on the same.

b) Students also had to collect the information on various codes and standards available for design of gate valves and its components.

c) Students were to refer API 60 valve standard to understand the design procedure for valve and thus come up with a design calculation for one class of valve (for one particular operating temperature and pressure.). Here students came up with a design report.

d) Design report consisted of gate valve details, design procedure, designed dimensions of parts of gate valves and detailed 2D drawings of designed parts of valve according to designed dimensions and tolerances.

\section{Assessment And Results:}

\section{A. Engineering Design Lab (3rd semester)}

Assessment for open ended lab exercise (for year 2013-14) for modelling and assembly of gate valve was done for 18 marks out of 80 continuous internal evaluation (CIE) marks. Students were evaluated for their drafting, modelling and assembly skills. Average of $65.71 \%$ was observed for class strength of 69 students.

A comparison can be made with the same task of open ended exercise for year 2012-13 where student groups performed 3D modelling and assembly of products of their choice; here the class average evaluated for 10 CIE marks was observed as $58.62 \%$ for a class strength of 80 students.

Thus an improvement in CIE marks of $7.09 \%$ can be observed by adopting contextual approach.

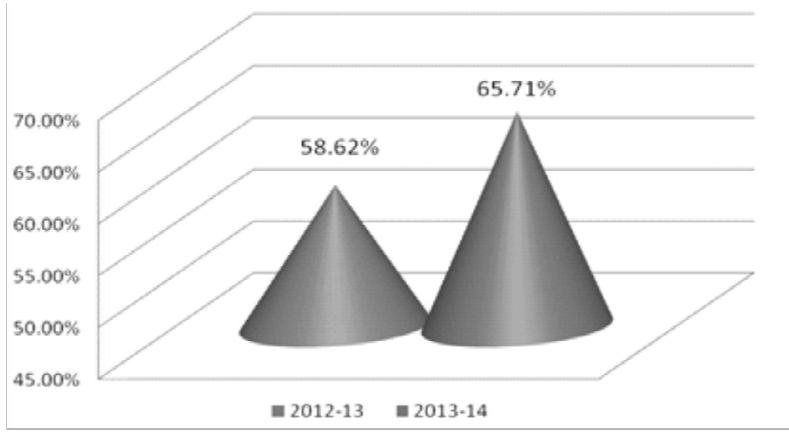

Fig. 1.Comparison of average open ended marks for 2012-13 and 2013-14
A. Design of Machine Elements (4th semester theory)

Assessment of the self study component for the course Design of Machine Elements was carried out for 25 marks, which consisted of a quiz (5 marks) and writing a design report (20 marks). Quiz measured individual student's understanding of theoretical aspects of valves and design report measured the design and co-ordination capabilities amongst student groups.

Thus the class average for quiz and design report for 71 students was observed to be $72 \%$ and $71.35 \%$ respectively (Fig 2).

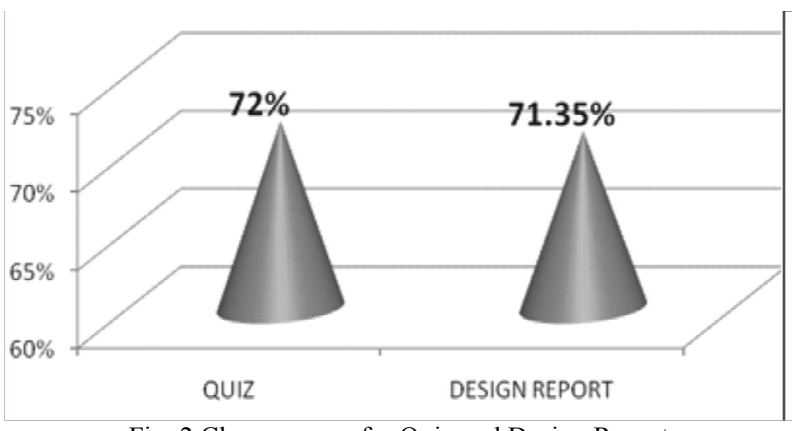

Fig. 2.Class average for Quiz and Design Report 


\section{Conclusions}

Although the process involved problems, the overall benefit to student understanding proved to be gratifying. The students' level of confidence to solve complex engineering problems was seen to be enhanced as they learnt the concepts in context and hence became more rational in applying the knowledge that they have acquired. Students were collectively able to tackle few complex situations in modelling and design activities as they approached the problem practically.

Few shortcomings during the project were observed as follows:

Time management for students was a problem as open ended exercise was conducted during the last four working weeks. In self study component, students faced problems in referring to API 60 due to its scope of use, availability of other reference standards has to be made for a better results.

Thus this innovative teaching method gave an opportunity for students and the staff to co-relate and apply the design concepts learnt in theory course to the context of industrial gate valve to enhance engineering knowledge/skills..

\section{References}

[1] B B Kotturshettar and Gururaj Fattepur , Contextual Integration of Industrial \& Production Engineering Curriculum, ICTIEE, 2014.

[2] Hewitt R.W., Using a Two-Cycle Engine to Integrate Manufacturing Engineering Technology Curriculum, ASEE Southeast Section Conference, (2007).

[3] Ziemian C. W., A Systems Approach to Manufacturing as implemented within a Mechanical Engineering Curriculum, International Journal of Engineering Education, Vol. 17, No. 6, pp. 558-568, (2001).

[4] Dr. Hamid Rad, Reverse engineering as a learning tool in design process, American Society for Engineering Education, Washington State University, Vancouver 2012. 